\title{
Investigation of Hot Deformation Behavior of SNCM8 Alloy Steel
}

\author{
Naiyanut Jantepa, Surasak Suranuntchai* \\ Department of Tool and Materials Engineering, Faculty of Engineering, King Mongkut's University of Technology Thonburi, \\ Bangkok, Thailand \\ Email: *surasak.sur@kmutt.ac.th
}

How to cite this paper: Jantepa, N. and Suranuntchai, S. (2021) Investigation of Hot Deformation Behavior of SNCM8 Alloy Steel. World Journal of Mechanics, 11, 17-33.

https://doi.org/10.4236/wjm.2021.113003

Received: March 20, 2019

Accepted: March 23, 2021

Published: March 26, 2021

Copyright $\odot 2021$ by author(s) and Scientific Research Publishing Inc. This work is licensed under the Creative Commons Attribution International License (CC BY 4.0).

http://creativecommons.org/licenses/by/4.0/

(c) (i) Open Access

\begin{abstract}
Plastic flow behavior of the SNCM8 steel was investigated by performing hot compression tests within the temperature range of $850^{\circ} \mathrm{C}$ to $1200^{\circ} \mathrm{C}$ and strain rates of $0.01 \mathrm{~s}^{-1}$ to $10 \mathrm{~s}^{-1}$. Constitutive modeling based on dynamic recrystallization was established, in which Cingara equation was applied to represent work hardening up to peak stress and Avrami equation to describe dynamic softening beyond peak stress up to steady state. It was found that stress-strain responses predicted by the combined model fairly agreed with experimentally resulted curves for the particular conditions. The correlation coefficient $(R)$ of 0.9485 and average absolute relative error $(A A R E)$ of $2.3614 \%$ was calculated for the modeled flow curves.
\end{abstract}

\section{Keywords}

SNCM8 Alloy Steel, Hot Deformation, Dynamic Recrystallization, Cingara Equation, Avrami Equation

\section{Introduction}

SNCM8 alloy is a commercial medium carbon Ni-Cr-Mo alloy steel. Due to its good balance of high strength, excellent toughness and wear resistance, this steel has been widely used for several general-purpose parts including automotive components, heavy-duty axles and gears, shaft and structural parts. Generally, the steel alloy is worked and fabricated at elevated temperatures [1]. During industrial hot forming processes of metals and alloys, components are usually subjected to extensive strain, strain rate and temperature histories. Understanding plastic flow behavior of metal alloys at high temperatures is thus of great importance for part designers and manufacturers. In order to investigate workability and to establish optimum hot deformation processing parameters for 
aimed alloys, a large number of works have been done by carrying out thermo-mechanical experiments, like compression, tension and torsion test over a wide range of forming temperature and strain rate. Materials constitutive equations have been developed for describing the hot deformation characteristics. All introduced materials models could be divided into three categories, namely, phenomenological, physical based and artificial neural network models, which show different approaches, prediction capabilities and scopes of application [2] [3]. Flow behavior of alloys at elevated temperatures has significant influences on designing a material forming process with regard to its efficiency of consumed deformation energy, final properties due to microstructure evolution. Therefore, it became very important to obtain an accurate description of flow stresses, although they are affected by several factors such as deformation temperature, strain rate, strain and alloying elements. Numerous works concerning flow curve modeling for representing plastic flow stresses of metals and alloys and their applications in Finite Element (FE) simulations have been provided [4]-[13]. In some investigations, basic constitutive models have been extended or modified for different alloys by considering effects of particular forming process parameters such as strain rates [11] [14] in order to obtain more precise predictions of the flow behavior, as presented in [15] [16]. As an example, in [8] a mathematical model was developed to predict stress-strain curves of a Ti-IF steel alloy during hot deformation. This model was based on a phenomenological representation of the shape of stress-strain responses and traditional constitutive equations which incorporated the power law. Here, these equations were expressed in terms of peak stress, peak strain, steady state stress and one additional parameter. It was found that the stress-strain curves of the Ti-IF steel calculated by this model were in good agreement with experimental results.

Those developed stress-strain relationships for predicting flow stress curves using peak stress, peak strain and four constants that were independent from deformation conditions could be simply calculated by non-linear regression of one or more experimental stress-strain curves [15]. Although predictions by using such type of stress-strain equations became more accurate than those by using the hyperbolic sine equation, it still showed a lack of strong physical background. Dynamic Recrystallization (DRX) flow curves of a 17-4 PH stainless steel were modeled and generalized using constitutive equations based on DRX description of Avrami model in [17]. By this manner, flow softening of the steel was directly related to the DRX volume fraction, in which the DRX time was determined according to definition of strain rate. It was shown that the Avrami kinetics was well suitable for extrapolating flow curves up to higher strains. This approach was useful in order to overcome restrictions of some deformation processes, such as hot compression. Reliability of each compared model was then evaluated by means of the Root Mean Square Error (RMSE), for example. Dynamic recrystallization of austenite in the Cu-bearing HSLA-100 steel was investigated by hot compression testing within the temperature range of $850^{\circ} \mathrm{C}$ $1150^{\circ} \mathrm{C}$ and strain rate range of $0.001-1 \mathrm{~s}^{-1}$ [18]. Stress and strain responses of 
the determined DRX flow behaviors were successfully correlated to the Zener-Hollomon parameter, $Z$, by power-law equations. In this case, the exponential equation provided a more precise dependence of flow stress on $Z$ parameter than the hyperbolic sine equation. Furthermore, activation energy and kinetics of the DRX could be apparently described by an Avrami-type equation. Hot working behavior of the $26 \mathrm{NiCrMoV} 14-5$ steel was examined by hot compression tests for the temperature range between $850^{\circ} \mathrm{C}$ and $1150^{\circ} \mathrm{C}$ and strain rate between 0.001 and $1 \mathrm{~s}^{-1}$ [19]. Obtained flow curves at temperatures higher than $1000^{\circ} \mathrm{C}$ exhibited typical dynamic recrystallization, whereas those at lower temperatures represented work hardening without any indication of dynamic recrystallization. The flow stresses were subsequently correlated with strain rates and temperatures using the hyperbolic sine function. It was observed that flow curves at high temperatures represented by a combination of Cingara and Avrami equations were considerably different from experimentally determined curves. Regarding low work hardening rate and increasing flow stress at the temperatures below $1000^{\circ} \mathrm{C}$, possibility of deformation-induced precipitation was supposed. To verify the potential of precipitation in the material stress relaxation tests were performed for different temperature ranges. According to the results different dependencies of flow stress on temperature at low and high temperature conditions were considered.

In this study, stress-strain curves of the SNCM8 steel were investigated using hot compression tests, which were carried out at the temperatures of $850^{\circ} \mathrm{C}$, $950^{\circ} \mathrm{C}, 1050^{\circ} \mathrm{C}, 1150^{\circ} \mathrm{C}$ and $1200^{\circ} \mathrm{C}$ with the strain rates of $0.01,0.1,1$ and $10 \mathrm{~s}^{-1}$. By the flow curve modeling, experimentally determined stress-strain responses were predicted using two different constitutive approaches. Firstly, the hyperbolic sine equation was used to describe relationships between flow stresses, plastic strains, strain rates and temperatures. Secondly, the model according to the Cingara equation was applied for representing the flow curves up to their peak points. Then, successive flow stresses were characterized by the Avrami equation, which was based on the DRX kinetics model [17] [19]. Numerically calculated stress-strain curves were compared with the experimental curves and evaluated using the Average Absolute Relative Error ( $A A R E)$ method.

\section{Experimental Procedure and Material Testing}

In this work, a commercial steel grade SNCM8 was investigated, for which the chemical composition was given in Table 1 . Cylindrical test specimens of the examined steel with a diameter of $5 \mathrm{~mm}$ and a height of $10 \mathrm{~mm}$ were prepared. Hot compression tests were carried out on a Baehr DIL-805 deformation dilatometer at five different temperatures that were $850^{\circ} \mathrm{C}, 950^{\circ} \mathrm{C}, 1050^{\circ} \mathrm{C}, 1150^{\circ} \mathrm{C}$ and $1200^{\circ} \mathrm{C}$ and four different strain rates that were $0.01,0.1,1$ and $10 \mathrm{~s}^{-1}$. The temperature-time diagram of the hot compression tests was depicted in Figure 1. By the tests, each specimen was firstly heated up to the given temperatures with the heating rate of $10^{\circ} \mathrm{C} / \mathrm{s}$. Then, it was held at those temperatures for $1 \mathrm{~min}$ 
Table 1. Chemical composition of the investigated steel (wt \%).

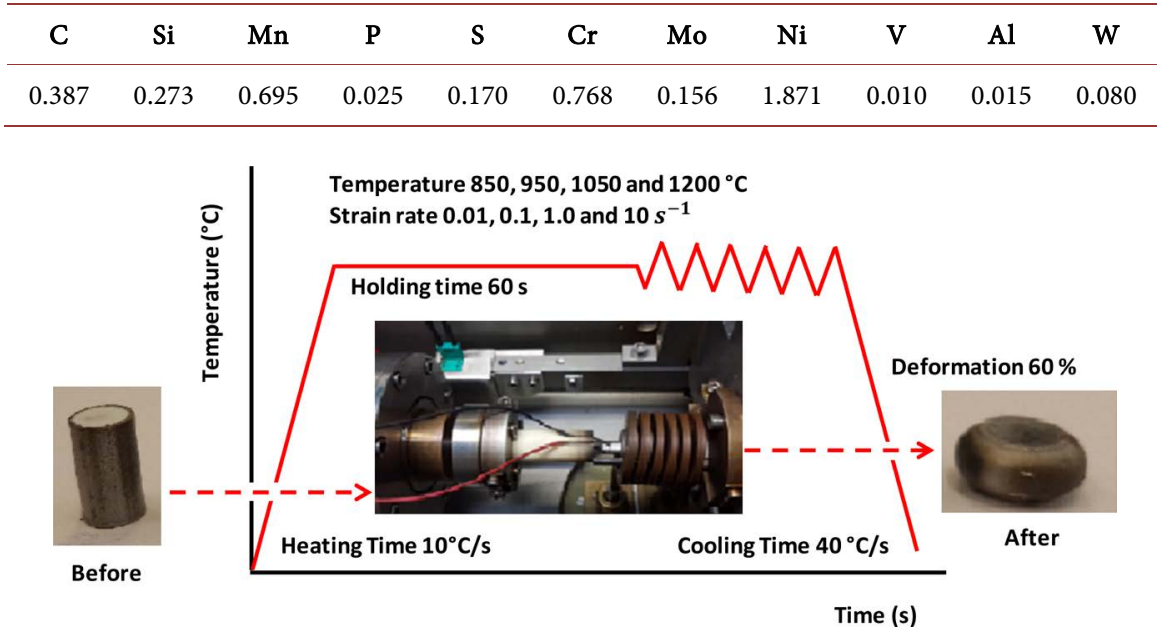

Figure 1. Experimental procedure of hot compression test.

in order to obtain homogeneous temperature distribution before compression. The specimens were subsequently upset to a height reduction of $60 \%$. During the hot compression tests, glass powder as lubricant was applied at the contact surfaces between specimens and dies for minimizing friction. To reveal recrystallized grain structures, specimens were also rapidly cooled in nitrogen gas directly after various stages of compression from the true strain of 0.1 up to 0.9. Finally, the quenched specimens were sliced along the axial section. The sectioned samples were polished and etched with saturated picric acid and corresponding micrographs were taken by optical microscope.

\section{Modeling of Stress-Strain Behavior}

\subsection{Flow Characteristics at High Temperatures}

Flow curves experimentally determined from hot compression tests were shown in Figure 2(a) and Figure 2(b) for different strain rates and temperatures. It could be seen that most stress-strain responses exhibited typical DRX characteristic, in which single peak stress occurred and was followed by a gradual drop towards steady-state stress. However, for this steel, the peak became less obvious when the strain rate or deformation temperature increased. The decline of flow stresses with forming temperature was primarily attributed to enhancement of the rate of restoration processes and consequently led to a decrease in strain hardening rate of the material. Additionally, DRX took place, when a critical strain was reached, and caused a further material softening. Since formation of DRX nuclei became easier at higher deformation temperatures, the critical strain for initiation of DRX typically increased at lower temperatures, as seen in Figure 2(b) and Table 2. Some discrepancies were noticed at the low temperature of $850^{\circ} \mathrm{C}$. Moreover, by rising forming temperatures mobility of grain boundaries increased and as a result, the rate of DRX was accelerated. Therefore, both strains, at which peak stress and stress at steady state were achieved, or so-called 

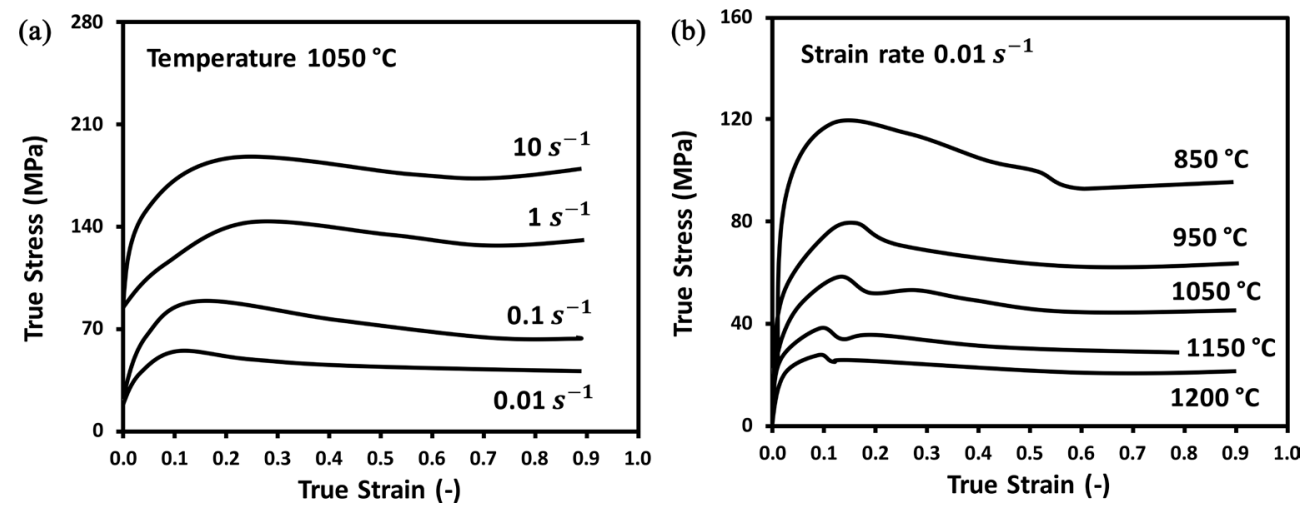

Figure 2. Determined true stress-true strain curves of SNCM8 steel at various temperatures and strain rates (a) at the temperature of $1050^{\circ} \mathrm{C}$ and (b) at the strain rate of $0.01 \mathrm{~s}^{-1}$.

Table 2. Values of peak stress $\left(\sigma_{p}\right)$ and peak strain $\left(\varepsilon_{p}\right)$ from different deformation conditions.

\begin{tabular}{ccccccc}
\hline \multirow{2}{*}{ Strain rate $\left(\mathrm{s}^{-1}\right)$} & \multicolumn{5}{c}{ Temperature $\left({ }^{\circ} \mathrm{C}\right)$} \\
\cline { 3 - 7 } & 0.01 & 120.02 & 78.96 & 58.93 & 37.38 & 27.55 \\
& 0.1 & 214.17 & 146.03 & 89.41 & 63.39 & 51.11 \\
$\sigma_{p}$ & 1.0 & 278.38 & 206.98 & 144.22 & 93.10 & 77.22 \\
& 10 & 303.78 & 227.11 & 192.85 & 103.74 & 84.72 \\
& 0.01 & 0.1583 & 0.1628 & 0.1402 & 0.104 & 0.0905 \\
& 0.1 & 0.2442 & 0.2352 & 0.1673 & 0.1312 & 0.1402 \\
& 1.0 & 0.4206 & 0.3799 & 0.2940 & 0.2216 & 0.1764 \\
$\varepsilon_{p}$ & 10 & 0.2487 & 0.3256 & 0.3121 & 0.2487 & 0.2307 \\
\hline
\end{tabular}

peak strain and steady state strain decreased with increasing deformation temperatures. At low strain rate conditions such as $0.01 \mathrm{~s}^{-1}$, stress-strain curves with multiple peaks were observed. This was a typical phenomenon of DRX process at low deformation rate due to repeated recrystallization and grain growth cycles that took place before reaching the steady state [1] [2] [3].

\subsection{Constitutive Description of Stress-Strain Behaviors}

In this work, constitutive modeling according to Arrhenius model was applied for describing relationship between flow stress, strain rate and temperature. Material constants of the examined steel for the constitutive equations were determined from experimental results of the hot compression tests. By this manner, effects of both temperature and strain rate on plastic flow behavior of the material could be described by the Zener-Hollomon parameter with an exponent-type equation. The Arrhenius model represented functions between the Zener-Hollomon parameters and material flow stress that could be expressed as [8]-[14]:

$$
Z=\dot{\varepsilon} \exp \left(\frac{Q}{R T}\right)
$$




$$
\dot{\varepsilon}=A F\left(\sigma_{p}\right) \exp \left(-\frac{Q}{R T}\right)
$$

where

$$
F(\sigma)=\sinh (\alpha \sigma)^{n}
$$

$\sigma$ is the material flow stress in $\mathrm{MPa}$ for a given strain. $R$ is the universal gas constant $\left(8.31 \mathrm{~J} \cdot \mathrm{mol}^{-1} \cdot \mathrm{K}^{-1}\right) . T$ is the absolute temperature in $K . \dot{\varepsilon}$ is the strain rate $\left(\mathrm{s}^{-1}\right) . Q$ is the activation energy during hot deformation $\left(\mathrm{kJ} \cdot \mathrm{mol}^{-1}\right) . A, \alpha$ and $n$ are the material constants, and $\alpha=\beta / n$. In this work, values of peak stress $\left(\sigma_{p}\right)$ from each condition were taken into account for the calculations. It was previously found that results obtained by using incremental flow stress values were similar to those only from the peak stress. Moreover, the hyperbolic-sine law, as provided in Equation (3) was applied, since it was more representative and commonly used. In the following, procedure for determining the material constants by considering the peak stresses was shown. Firstly, relationships between flow stresses and strain rates were described as:

$$
\begin{aligned}
& \ln \sigma=\frac{1}{n} \ln \dot{\varepsilon}-\frac{1}{n} \ln B \\
& \sigma=\frac{1}{\beta} \ln \dot{\varepsilon}-\frac{1}{\beta} \ln B^{\prime}
\end{aligned}
$$

$B$ and $B$ are materials constants that were independent from the forming temperatures. Then, substituting values of the flow stress at the peak points and corresponding strain rates into Equations (4) and (5). This resulted in relationships between flow stresses and strain rates, as illustrated in Figure 3(a) and Figure 3(b).

For a given constant temperature, the values of $n$ and $\beta$ were then derived from slopes of the regression lines in the $\ln \sigma-\ln \dot{\varepsilon}$ and $\sigma-\ln \dot{\varepsilon}$ diagrams, respectively. Here, flow stresses obtained from the hot compression tests could be represented by a group of parallel and straight lines. As seen, by using the linear regression method, the parameters $n$ and $\beta$ could be approximately determined for different deformation temperatures. Afterwards, the mean values of $n$ and $\beta$ of
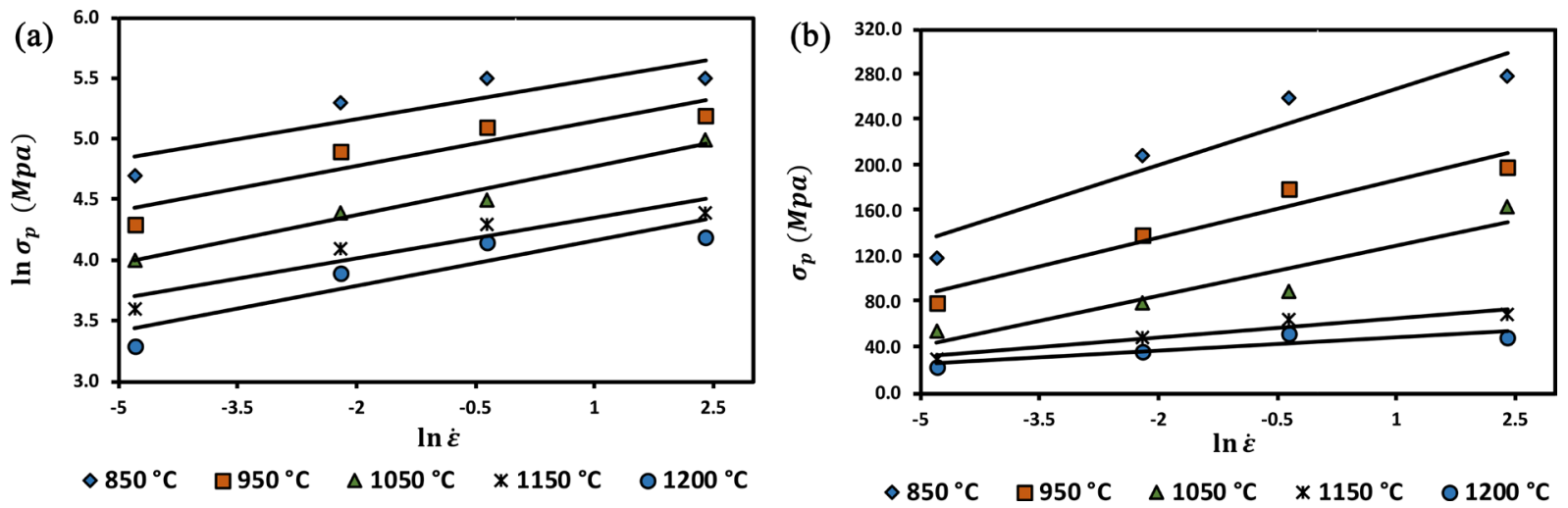

Figure 3. Relationships between (a) $\ln \sigma_{p}$ and $\ln \dot{\varepsilon}$ and (b) $\sigma_{p}$ and $\ln \dot{\varepsilon}$. 
7.073 and $0.071 \mathrm{MPa}$, were calculated for all examined temperatures, respectively. For the SNCM8 steel, the obtained parameter $\alpha=\beta / n$ was equal to $0.011 \mathrm{MPa}^{-1}$. For the peak stress, Equation (2) could be rewritten as following.

Taking natural logarithm to both side of Equation (2) gave

$$
Q / R T=\ln A-\ln \dot{\varepsilon}+n \ln \left[\sinh \left(\alpha \sigma_{p}\right)\right] .
$$

The apparent activation energy $Q$ was calculated through differentiating Equation (6).

$$
Q=R\left[\frac{\partial \ln \dot{\varepsilon}}{\partial \ln \left[\sinh \left(\alpha \sigma_{p}\right)\right]}\right]_{T}\left[\frac{\partial \ln \left[\sinh \left(\alpha \sigma_{p}\right)\right]}{\partial(1 / T)}\right]_{\dot{\varepsilon}}
$$

The values of forming temperatures, strain rates and corresponding stresses were substituted into Equation (6). Relationships of $\ln \left[\sinh \left(\alpha \sigma_{p}\right)\right]-1 / T$ and $\ln \left[\sinh \left(\alpha \sigma_{p}\right)\right]-\ln \dot{\varepsilon}$ could be evaluated at constant strain rate and temperature and then plotted in Figure 4(a) and Figure 4(b), respectively. Generally, the activation energy values $Q$ was determined from the slopes of parallel lines in the $\ln \left[\sinh \left(\alpha \sigma_{p}\right)\right]-1 / T$ and $\ln \left[\sinh \left(\alpha \sigma_{p}\right)\right]-\ln \dot{\varepsilon}$ plots. As before, from the regression lines in Figure 4(a) and Figure 4(b), the values $Q$ was directly calculated for different strain rates and forming temperatures. For the investigated steel, the averaged value of the activation energy $Q$ of $385.6 \mathrm{~kJ} \cdot \mathrm{mol}^{-1}$ was obtained. For the peak stresses, Equation (1) could be expressed now as following.

$$
Z=\dot{\varepsilon} \exp \left(\frac{Q}{R T}\right)=A\left[\sinh \left(\alpha \sigma_{p}\right)\right]^{\eta}
$$

Then, taking the logarithm to both sides of Equation (8) gave

$$
\ln Z=\ln A+n \ln \left[\sinh \left(\alpha \sigma_{p}\right)\right]
$$

From the experimental results, relationship between $\ln \left[\sinh \left(\alpha \sigma_{p}\right)\right]$ and $\ln Z$ could be determined and plotted in Figure 5. Then, the values of $\ln A$ and $n$ were the intercept and slope of the $\ln Z-\ln \left[\sinh \left(\alpha \sigma_{p}\right)\right]$ plot, respectively. Now, the values $A$ of $1.019 \times 10^{14} \mathrm{~s}^{-1}$ could be directly calculated. Additionally,
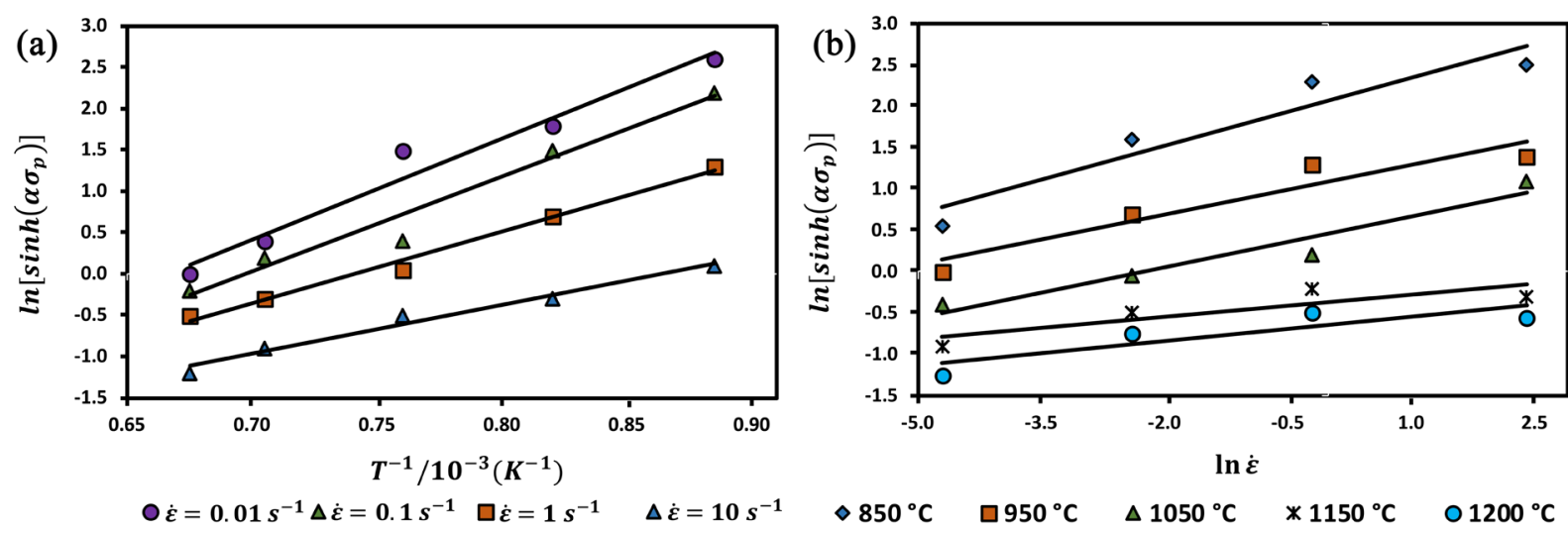

Figure 4. Relationships between (a) $\ln \left[\sinh \left(\alpha \sigma_{p}\right)\right]$ and $1 / T$ and (b) $\ln \left[\sinh \left(\alpha \sigma_{p}\right)\right]$ and $\ln \dot{\varepsilon}$. 


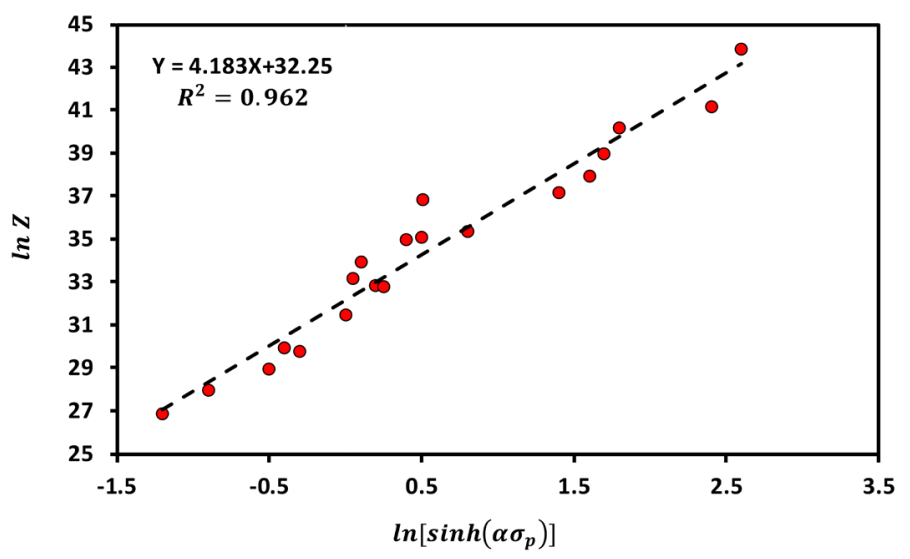

Figure 5. Relationship between $\ln \left[\sinh \left(\alpha \sigma_{p}\right)\right]$ and $\ln Z$ for peak stresses from hot compression tests.

the mean value of $n$ from Equation (9) was computed to be 4.18.

Finally, relationships between $Q, \ln A, \beta, n, \alpha$ and plastic strain for the investigated steel SNCM8 were fitted in a polynomial form. From Equation (8) the flow stresses $\sigma$ were subsequently written as a function of the Zener-Hollomon parameter. Also, the proposed constitutive model could be summarized in the following equation.

$$
\dot{\varepsilon}=1.019 \times 10^{14}[\sinh (0.011 \sigma)]^{4.18} \exp (-385.6 / R T)
$$

Then, the flow stress of the examined steel could be now expressed as a function of the $Z$ parameter under consideration of the hyperbolic law.

$$
\sigma=90.9 \times\left\{\left(\frac{Z}{1.019 \times 10^{14}}\right)^{\frac{1}{4.18}}+\left[\left(\frac{Z}{1.019 \times 10^{14}}\right)^{\frac{2}{4.18}}+1\right]^{\frac{1}{2}}\right\}
$$

\subsection{Characteristic Points of Flow Curves}

Peak state and onset of steady state deformation were the important characteristic points of a typical flow curve with DRX. Using calculated value of the activation energy $Q$, values of these states could be determined regarding to the $\mathrm{Z}$ parameter. Figure 6(a) and Figure 6(b) showed peak strain $\left(\varepsilon_{p}\right)$, peak stress $\left(\sigma_{p}\right)$ and steady state strain $\left(\varepsilon_{s s}\right)$, steady state stress $\left(\sigma_{s s}\right)$ as a function of the ZenerHollomon parameter Z. As expected, DRX was actually shifted to a higher strain and stress as temperature decreased or strain rate increased. Equations (12)-(15) were particularly proposed in order to simply determine the start and finish of the DRX of the investigated steel during hot forming independence on the $Z$ parameter [15] [17].

$$
\begin{aligned}
& \varepsilon_{p}=0.0140 \cdot Z^{0.77} \\
& \varepsilon_{s s}=0.2731 \cdot Z^{0.23} \\
& \sigma_{p}=0.7445 \cdot Z^{0.143}
\end{aligned}
$$




$$
\sigma_{s s}=0.4343 \cdot Z^{0.154}
$$

According to Equations (14) and (15), a linear relationship between peak stress and steady state stress was obtained, as given in Equation (16) and depicted in Figure 7. This equation was further used for modeling purpose.

$$
\sigma_{s s}=0.961 \sigma_{p}
$$

\subsection{Flow Curve Modeling up to Peak Stress}

In this work, experimentally determined flow curves were firstly described using the Cingara equation [17] [19], as expressed in Equation (17), up to their corresponding peak stresses of each condition.

$$
\sigma=\sigma_{p}\left[\left(\frac{\varepsilon}{\varepsilon_{p}} \exp \left(1-\frac{\varepsilon}{\varepsilon_{p}}\right)\right)\right]^{c}
$$

Taking natural logarithm to this equation yielded the following equation.

$$
\ln \left(\frac{\sigma}{\sigma_{p}}\right)=C\left[1-\frac{\varepsilon}{\varepsilon_{p}}+\ln \left(\frac{\varepsilon}{\varepsilon_{p}}\right)\right]
$$

From Equation (18), relationship between $\ln \left(\sigma / \sigma_{p}\right)$ and $1-\left(\varepsilon / \varepsilon_{p}\right)+\ln \left(\varepsilon / \varepsilon_{p}\right)$
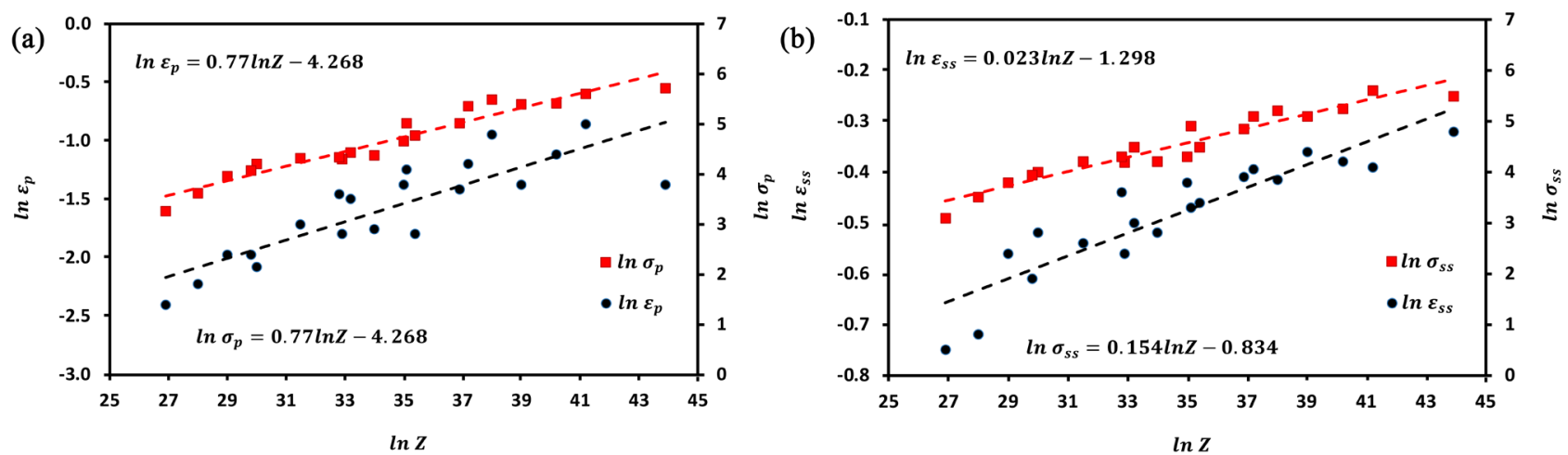

Figure 6. Effects of the Zener-Hollomon parameter on the characteristic points of flow curve at (a) peak point and (b) steady state point.

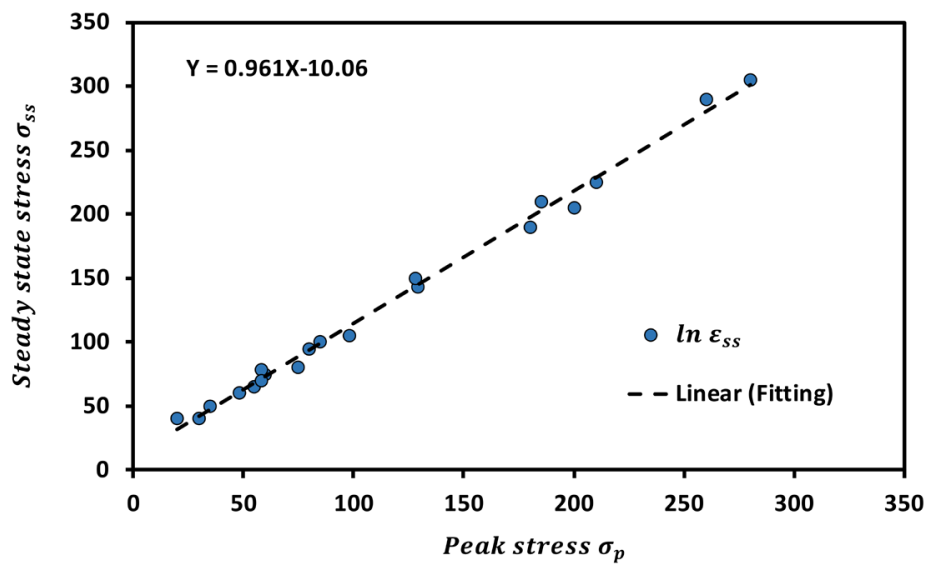

Figure 7. Relationship between peak and steady state stresses of the investigated steel. 
could be obtained and plotted for determining the constant $\mathrm{C}$ by a linear regression, as illustrated for the temperature of $1050^{\circ} \mathrm{C}$ and strain rate of $0.1 \mathrm{~s}^{-1}$ in Figure 8. Subsequently, the average value of 0.382 was calculated for the individual constants $C$ of each condition, as summarized in Table 3. Then, true stress-strain curves were modeled using the Cingara equation up to the peak stresses for every tested forming condition and compared with the experimental curves. The results were acceptable, as depicted for the strain rate of $0.1 \mathrm{~s}^{-1}$ and different temperatures in Figure 9.

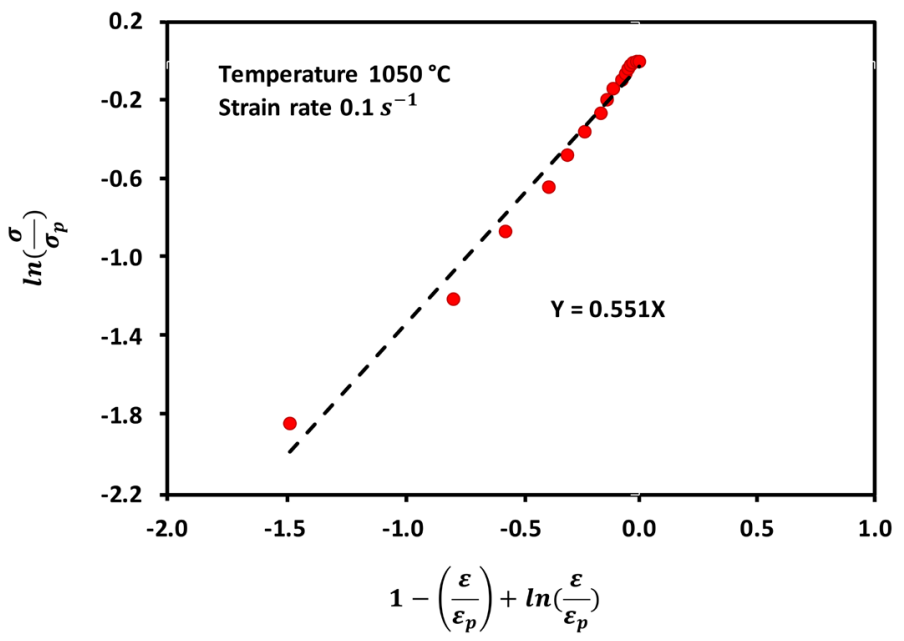

Figure 8. Plot for calculation of the Cingara constant $C$.

Table 3. Values of the constant $C$ of the Cingara equation for each testing condition.

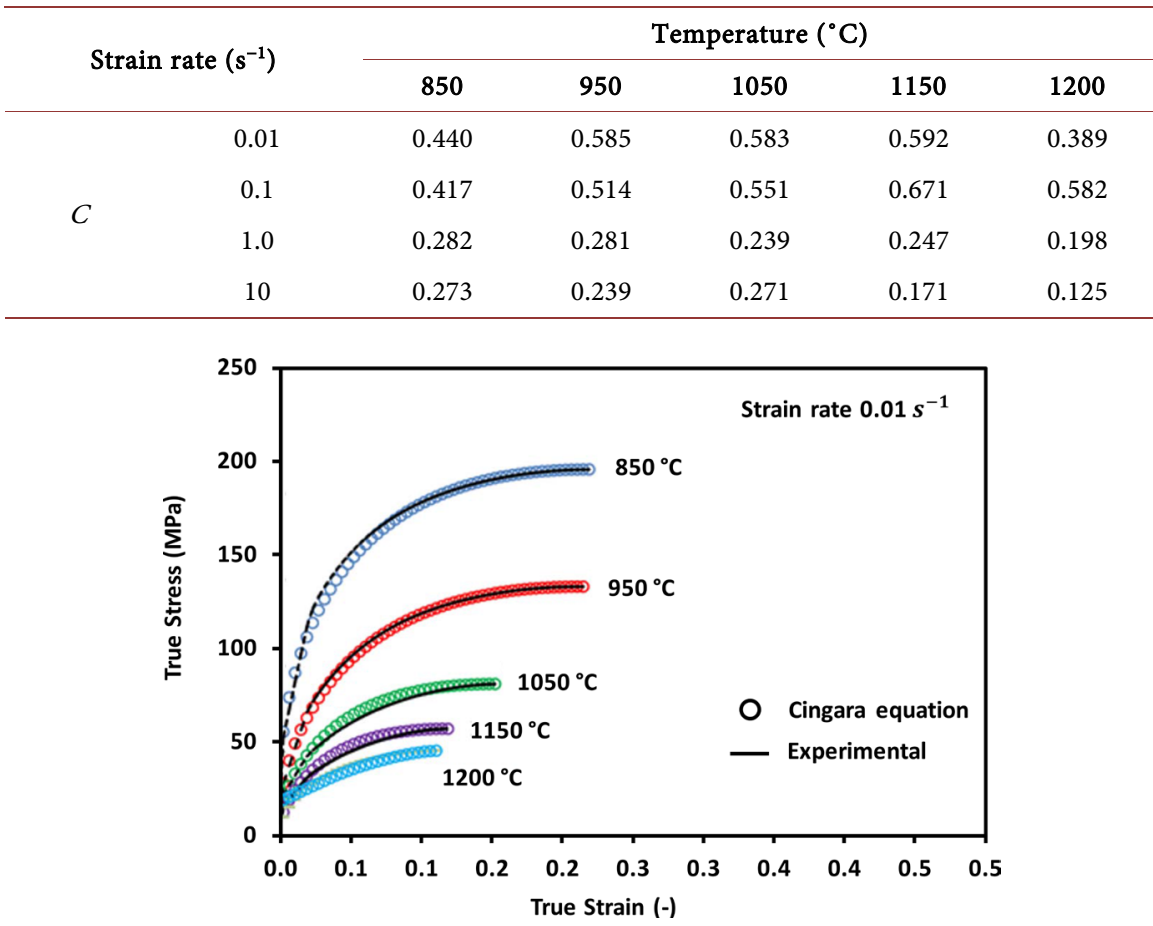

Figure 9. Comparison of stress-strain curves up to peak stresses obtained by experiments and Cingara equation for the strain rate of $0.1 \mathrm{~s}^{-1}$ and different temperatures. 


\subsection{Flow Curves Modeling after Peak Stress}

As seen in Figure 2, DRX was the most significant softening mechanism that occurred in the investigated steel during hot deformation. Generally, it was so complex to determine the DRX fraction $X_{d}$ by microstructure observations. In this work, Avrami model was applied, in which the $X_{d}$ value could be directly derived from the experimental stress-strain data. The DRX fraction was described as a function of different characteristic values of the flow curve, as expressed in Equation (19) [17].

$$
X_{d}=\frac{\sigma_{p}-\sigma}{\sigma_{p}-\sigma_{s s}}
$$

$\sigma_{p}$ is the peak stress, $\sigma_{s s}$ is the steady state stress. The $\left(\sigma_{p}-\sigma\right)$ term indicated material flow softening from the peak point to any flow stress $\sigma$, whereas the $\left(\sigma_{p}-\sigma_{s s}\right)$ term represented the maximum achievable softening. This flow softening was directly related to the DRX volume fraction $X_{d}$, in which effects of DRV on flow softening were not considered here [19]. Moreover, it was supposed that initiation of DRX took place at the peak strain. By this consideration, calculations according to the Avrami equation could provide results with acceptable accuracy [18].

Thus, Equation (20) has been often used as the general form of the DRX kinetics model in alloy [17]-[22].

$$
X_{d}=1-\exp \left[(-k)\left(\frac{\varepsilon-\varepsilon_{c}}{\varepsilon_{p}}\right)^{n}\right]
$$

where $k, n$ are the material constants; $\varepsilon$ is the true strain; $\varepsilon_{c}$ is the critical strain and $\varepsilon_{p}$ is the peak strain. However, $\varepsilon_{c}$ was known as the critical strain for the initiation of DRX, but the flow softening intrinsically started at peak strain $\varepsilon_{p}$ [21].Therefore, Equation (20) could be transformed to Equation (21). In order to determine the values of $k$ and $n$, Equation (21) was rewritten by taking a double natural logarithm form, as shown in Equation (22).

$$
\begin{gathered}
X_{d}=1-\exp \left[(-k)\left(\frac{\varepsilon-\varepsilon_{p}}{\varepsilon_{p}}\right)^{n}\right] \\
\ln \ln \left(\frac{1}{1-X_{d}}\right)=\ln k+n \ln \left(\frac{\varepsilon-\varepsilon_{p}}{\varepsilon_{p}}\right)
\end{gathered}
$$

The relationship between $\ln \ln \left(1 /\left(1-X_{d}\right)\right)$ and $\ln \left(\left(\varepsilon-\varepsilon_{p}\right) / \varepsilon_{p}\right)$ under various deformation conditions was almost linear, as depicted in Figure 10. From this relationship, the values of $k$ and $n$ of 1.865 and 2.065, respectively, were obtained for the DRX kinetics model. Also, the DRX kinetics model for the investigated steel could be then established as following.

$$
X_{d}=1-\exp \left[-2.065\left(\frac{\varepsilon-\varepsilon_{p}}{\varepsilon_{p}}\right)^{1.865}\right]
$$




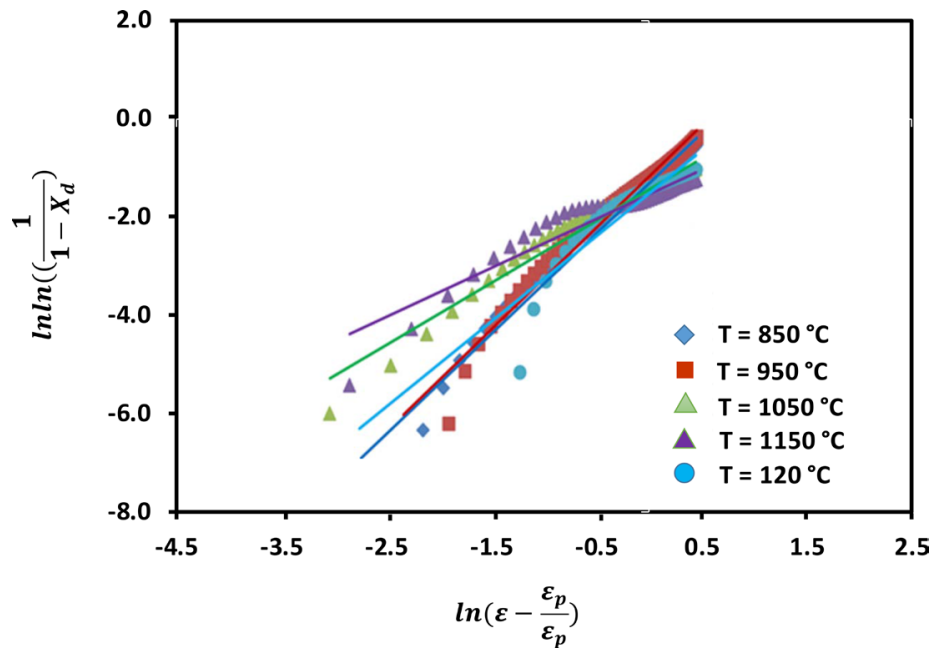

Figure 10. Determination of the constants $k$ and $n$ for different temperatures and strain rates.
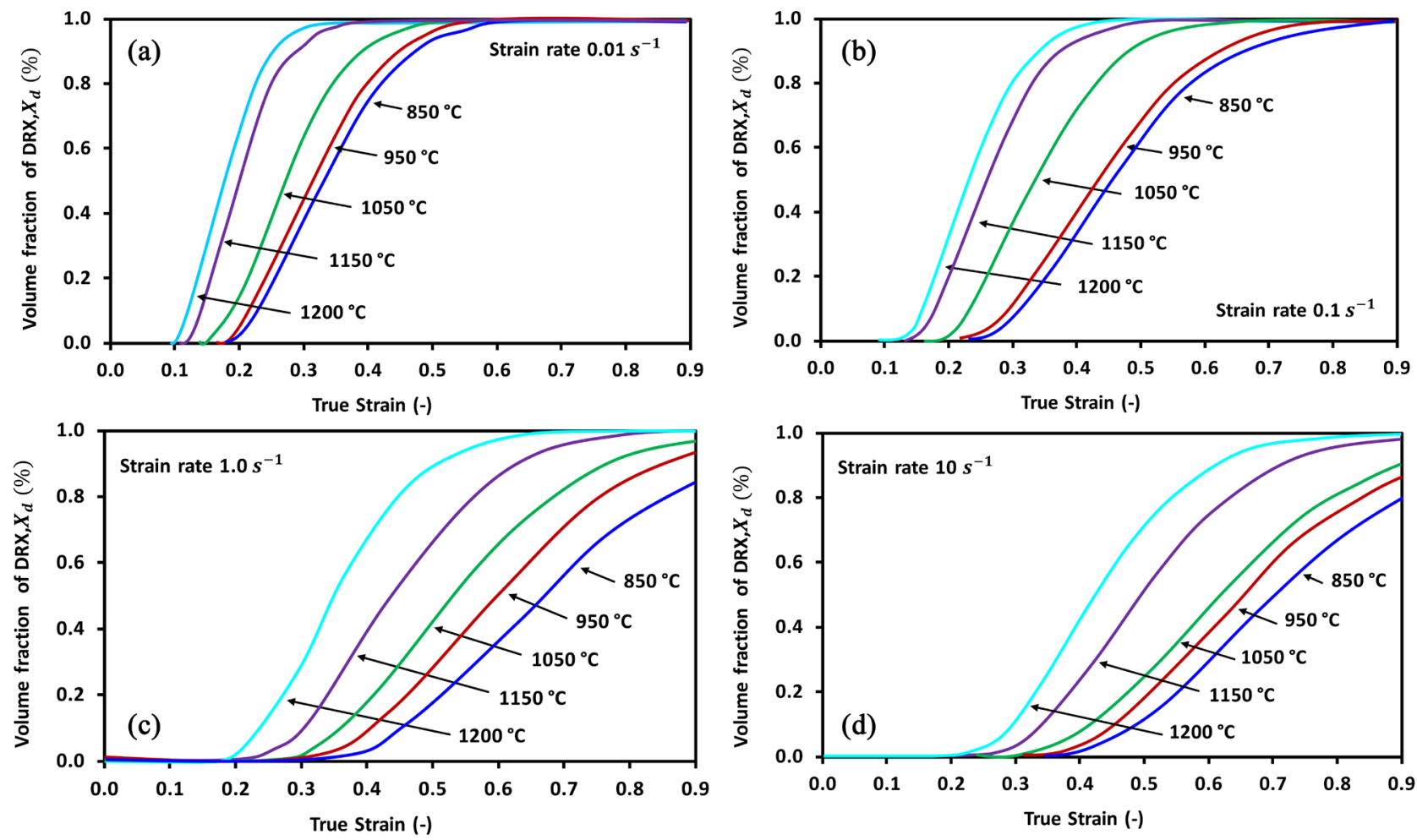

Figure 11. Predicted DRX volume fraction occurred under various deformation temperatures and strain rates of (a) $0.01 \mathrm{~s}^{-1}$, (b) $0.1 \mathrm{~s}^{-1}$, (c) $1.0 \mathrm{~s}^{-1}$ and (d) $10 \mathrm{~s}^{-1}$.

Based on the calculated results of this model, effects of deformation temperature, strain rate and strain on volume fraction of the occurred DRX were shown in Figure 11. It could be seen that the volume fractions of DRX increased with increasing strain. Additionally, the DRX rate obviously became higher at higher temperatures or lower strain rates. At the strain rates of 0.1 and $0.01 \mathrm{~s}^{-1}$, a completely recrystallized structure was predicted for all tested temperatures beyond the true strain of 0.9 . In contrast, at higher strain rates of 1 and $10 \mathrm{~s}^{-1}$, incom- 
plete recrystallization was shown for the lower temperature of $850^{\circ} \mathrm{C}, 950^{\circ} \mathrm{C}$ and $1050^{\circ} \mathrm{C}$.

According to Equation (19) to Equation (23) in combination with Equation (16), flow stresses after peak points could be expressed as:

$$
\sigma=\sigma_{p}-\left(\sigma_{p}-\sigma_{s s}\right) X_{d}
$$

According to Equation (24), Equation (21) and Equation (16), flow stresses beyond peak points could be given then as a function of the peak stress and peak strain as following.

$$
\sigma=0.961 \sigma_{p}+0.039 \sigma_{p} \exp \left[(-2.065)\left(\frac{\varepsilon-\varepsilon_{p}}{\varepsilon_{p}}\right)^{1.865}\right]
$$

The values of $\sigma_{p}, \varepsilon_{p}, k$ and $n$ were determined for each deformation condition and subsequently stress-strain curves were calculated by using Equation (25).

\subsection{Prediction of Flow Stress Curve}

In order to verify the introduced flow stress models, experimental and numerically predicted stress-strain results were compared. Figure 12 showed measured and calculated flow stress curves of the investigated steel SNCM8 for five different
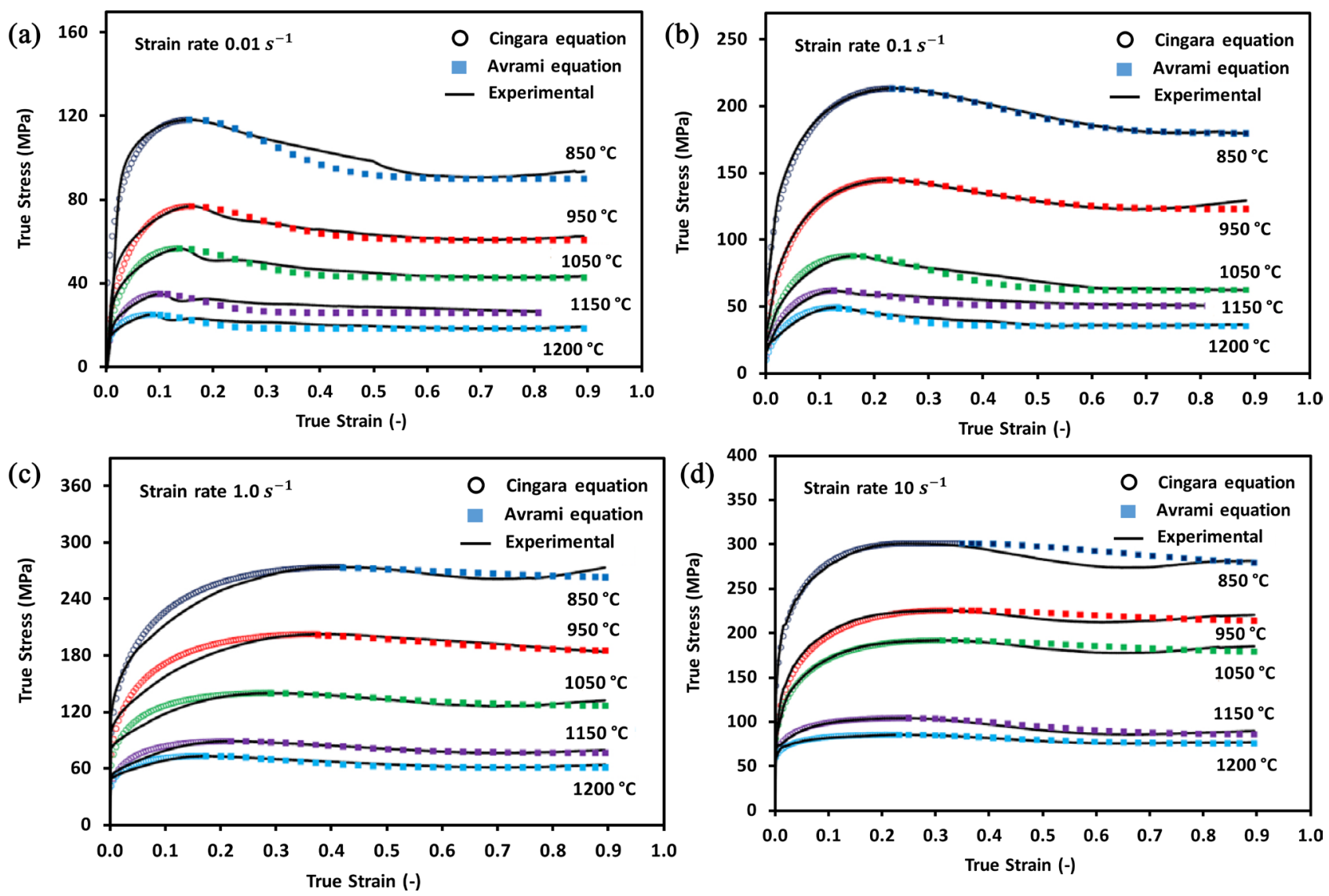

Figure 12. Comparisons between experimental and predicted stress-strain curves obtained from hot compression tests at different temperatures and strain rates of (a) $0.01 \mathrm{~s}^{-1}$, (b) $0.1 \mathrm{~s}^{-1}$, (c) $1.0 \mathrm{~s}^{-1}$ and (d) $10 \mathrm{~s}^{-1}$. 


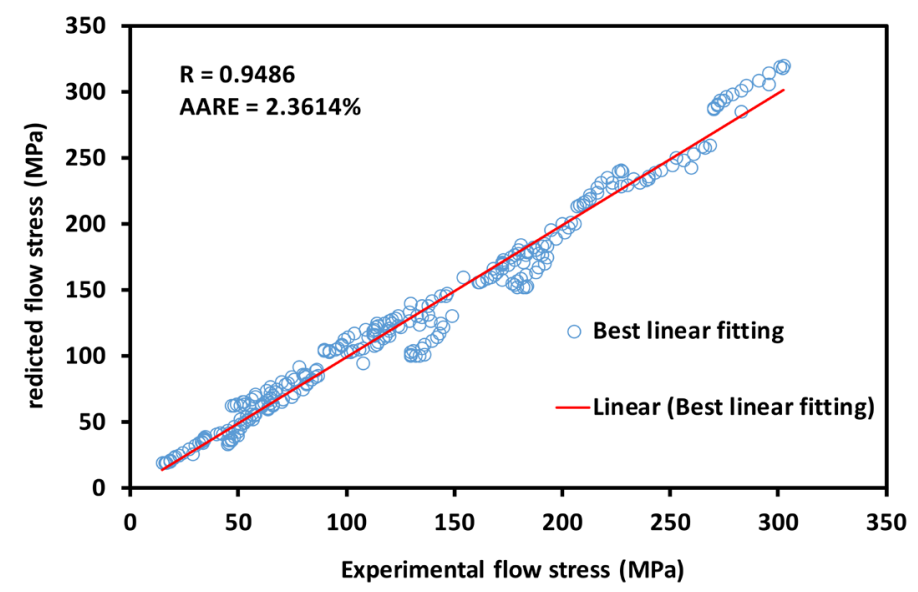

Figure 13. Correlation between the experimental and predicted flow stress data.

deformation temperatures and strain rates. It could be observed that flow stresses predicted by the proposed models were in good agreement with the experimental data for all entire ranges of examined deformation temperature and strain rate. $A$ scatter diagram of the predicted values against experimental results for all deformation conditions was provided in Figure 13, in which well correlation between calculated and experimental flow stress data was verified. Predictability of the approach was also evaluated by employing standard statistical parameters such as correlation coefficient $(R)$ and average absolute relative error $(A A R E)$. These parameters were both expressed as following.

$$
\begin{gathered}
R=\frac{\sum_{i=1}^{N}\left(P_{i}-\bar{P}\right)\left(E_{i}-\bar{E}\right)}{\sqrt{\sum_{i=1}^{N}\left(P_{i}-\bar{P}\right)^{2} \sum_{i=1}^{n}\left(E_{i}-\bar{E}\right)^{2}}} \\
A A R E=\frac{I}{N} \sum_{i=1}^{N}\left|\frac{E_{i}-P_{i}}{E_{i}}\right| \times 100
\end{gathered}
$$

$E$ is the experimental flow stress and $P$ is the predicted flow stress obtained from the introduced combined constitutive equations. $\bar{E}$ and $\bar{P}$ were the mean values of $E$ and $P$, respectively. $N$ is the total number of data used in this study. $R$ is a commonly employed statistical parameter and provided information on the reliability of linear relationship between the experimental and predicted data. Sometimes, the higher value of $R$ may not necessarily indicate a better performance, whereby tendency of the equation could be biased towards higher or lower values [17] [22]. The AARE was calculated through a comparison between relative errors and therefore was rather an unbiased statistical parameter that was more suitable for determining the predictability of the equations [17]. From Figure 13, the values of $R$ and $A A R E$ were calculated to be $0.9486 \%$ and $2.361 \%$ respectively, which exhibited high prediction capabilities of the developed combined constitutive models.

\section{Conclusions}

Hot compression tests of the steel alloy SNCM8 were conducted in the tempera- 
ture range of $850^{\circ} \mathrm{C}-1200^{\circ} \mathrm{C}$ and the strain rate range of $0.01-10 \mathrm{~s}^{-1}$. It was found that the strain rate and temperature significantly affected flow stress-strain behavior of this steel. The flow stress decreased with increasing deformation temperature and decreasing strain rate.

1) Stress-strain curves of the SNCM8 steel exhibited typical DRX phenomenon with single peak stress followed by a gradual fall towards steady state stress.

2) Constitutive equations were developed using the hyperbolic-sine type of the Arrhenius model for describing the stress-strain responses independence on the deformation temperatures and strain rates and following relationship was obtained.

$$
\dot{\varepsilon}=1.019 \times 10^{14}[\sinh (0.0110 \sigma)]^{4.1832} \exp (-385.584 / R T)
$$

3) Relationships between the characteristic points of flow stress and the parameter $Z$ were determined as $\varepsilon_{p}=0.0140 \cdot Z^{0.77}, \varepsilon_{s s}=0.2731 \cdot Z^{0.23}$, $\sigma_{p}=0.7445 \cdot Z^{0.143}, \sigma_{s s}=0.4343 \cdot Z^{0.154}$ and the linear function between the peak and steady state stress was $\sigma_{s s}=0.961 \sigma_{p}$.

4) The DRX flow curves obtained from experiments were successfully described by using a combination of Cingara and Avrami equations.

5) Predictability of the introduced combination approach of the Cingara and Avrami equations was evaluated in terms of the correlation coefficient $(R)$ and average absolute relative error $(A A R E)$. The $R$ and $A A R E$ were found to be $0.9486 \%$ and $2.3614 \%$ respectively, which indicated good prediction capabilities of the combined model.

\section{Acknowledgements}

The authors would like to acknowledge King Mongkut's University of Technology Thonburi through the "KMUTT $55^{\text {th }}$ Anniversary Commemorative Fund" and National Research Council of Thailand (NRCT) for the financial support. Also, sincere gratitude must be given to "S.B. - CERA Co., Ltd." for the material testing and the experiment part.

\section{Conflicts of Interest}

The authors declare no conflicts of interest regarding the publication of this paper.

\section{References}

[1] Lee, W.S. and Yeh, G.W. (1997) The Plastic Deformation Behavior of AISI 4340 Alloy Steel Subjected to High Temperature and High Strain Rate Loading Conditions. Journal of Materials Processing Technology, 71, 224-234. https://doi.org/10.1016/S0924-0136(97)00079-4

[2] Gronostajski, Z. (2000) The Constitutive Equations for FEM Analysis. Journal of Materials Processing Technology, 106, 40-44. https://doi.org/10.1016/S0924-0136(00)00635-X

[3] Lin, Y.C. and Chen, X.M. (2011) A Critical Review of Experimental Results and Constitutive Descriptions for Metals and Alloys in Hot Working. Materials \& De- 
sign, 32, 1733-1759. https://doi.org/10.1016/j.matdes.2010.11.048

[4] Lin, Y.C., Chen, M.S. and Zhong, J. (2008) Numerical Simulation for Stress/Strain Distribution and Microstructural Evolution in 42CrMo Steel during Hot Upsetting Process. Computational Materials Science, 43, 1117-1122. https://doi.org/10.1016/j.commatsci.2008.03.010

[5] Lin, Y.C. and Chen, M.S. (2009) Numerical Simulation and Experimental Verification of Microstructure Evolution in a Three-Dimensional Hot Upsetting Process. Journal of Materials Processing Technology, 209, 4578-4583. https://doi.org/10.1016/j.jmatprotec.2008.10.036

[6] Lin, Y.C., Chen, M.S. and Zhong, J. (2009) Effects of Deformation Temperatures on Stress/Strain Distribution and Microstructural Evolution of Deformed 42CrMo Steel. Materials \& Design, 30, 908-913. https://doi.org/10.1016/j.matdes.2008.05.010

[7] Laasraoui, A. and Jonas, J.J. (1991) Prediction of Steel Flow Stresses at High Temperatures and Strain Rates. Metallurgical Transactions A, 22, 1545-1558. https://doi.org/10.1007/BF02667368

[8] Ebrahimi, R., Zahiri, S.H. and Najafizadeh, A. (2006) Mathematical Modeling of the Stress-Strain Curves of Ti-IF Steel at High Temperature. Journal of Materials Processing Technology, 171, 301-305. https://doi.org/10.1016/j.jmatprotec.2005.06.072

[9] Lin, Y.C., Chen, M.S. and Zhong, J. (2008) Effect of Temperature and Strain Rate on the Compressive Deformation Behavior of $42 \mathrm{CrMo}$ Steel. Journal of Materials Processing Technology, 205, 308-315.

https://doi.org/10.1016/j.jmatprotec.2007.11.113

[10] Lin, Y.C., Chen, M.S. and Zhong, J. (2008) Prediction of 42CrMo Steel Flow Stress at High Temperature and Strain Rate. Mechanics Research Communications, 35, 142-150. https://doi.org/10.1016/j.mechrescom.2007.10.002

[11] Sanrutsadakorn, A., Uthaisangsuk, V., Suranuntchai, S. and Thossatheppitak, B. (2013) Constitutive Modeling of Flow Behaviour of AISI 4340 Steel under Hot Working Conditions. Applied Mechanics and Materials, 249-250, 863-869. https://doi.org/10.4028/www.scientific.net/AMM.249-250.863

[12] Mandal, S., Rakesh, V., Sivaprasad, P.V., Venugopal, S. and Kasiviswanathan, K.V. (2009) Constitutive Equations to Predict High Temperature Flow Stress in a Ti-Modified Austenitic Stainless Steel. Materials Science and Engineering. A, 500, 114-121. https://doi.org/10.1016/j.msea.2008.09.019

[13] Mirzadeh, H., Cabrera, J.M. and Najafizadeh. A. (2012) Modeling and Prediction of Hot Deformation Flow Curves. Metallurgical and Materials Transactions A, 43, 108-123. https://doi.org/10.1007/s11661-011-0836-3

[14] Lin, Y.C., Chen, M.S. and Zhong, J. (2008) Constitutive Modeling for Elevated Temperature Flow Behavior of 42CrMo Steel. Computational Materials Science, 42, 470-477. https://doi.org/10.1016/j.commatsci.2007.08.011

[15] Mirzadeh, H. and Najafizadeh, A. (2010) Flow Stress Prediction at Hot Working Conditions. Materials Science and Engineering: A, 527, 1160-1164. https://doi.org/10.1016/j.msea.2009.09.060

[16] Yin, F., Hua, L., Mao, H.J. and Han, X.H. (2013) Constitutive Modeling for Flow Behavior of GCr15 Steel under Hot Compression Experiments. Materials \& Design, 43, 393-401. https://doi.org/10.1016/j.matdes.2012.07.009

[17] Mirzadeh, H. and Najafizadeh, A. (2010) Extrapolation of Flow Curves at Hot Working Conditions. Materials Science and Engineering: A, 527, 1856-1860. https://doi.org/10.1016/j.msea.2009.11.013 
[18] Momeni, A., Arabi, H., Rezaei, A., Badri, H. and Abbasi, S.M. (2011) Hot Deformation Behavior of Austenite in HSLA-100 Microalloyed Steel. Materials Science and Engineering: $A$, 528, 2158-2163. https://doi.org/10.1016/j.msea.2010.11.062

[19] Mirzaee, M., Keshmiri, H., Ebrahimi, G.R. and Momeni, A. (2012) Dynamic Recrystallization and Precipitation in Low Carbon Low Alloy Steel 26NiCrMoV 14-5. Materials Science and Engineering: A, 551, 25-31.

https://doi.org/10.1016/j.msea.2012.04.063

[20] Wang, M.H., Li, Y.F., Wang, W.H., Zhou, J. and Chiba, A. (2013) Quantitative Analysis of Work Hardening and Dynamic Softening Behavior of Low Carbon Alloy Steel Based on the Flow Stress. Materials \& Design, 45, 384-392. https://doi.org/10.1016/j.matdes.2012.08.041

[21] Wei, H.L., Liu, G.Q., Xiao, X. and Zhang, M.H. (2013) Dynamic Recrystallization Behavior of a Medium Carbon Vanadium Microalloyed Steel. Materials Science and Engineering: $A, 573,215-221$. https://doi.org/10.1016/j.msea.2013.03.009

[22] Chen, F., Cui, Z.S. and Chen, S.J. (2011) Recrystallization of 30Cr2Ni4MoV Ultra-Super-Critical Rotor Steel during Hot Deformation. Part I: Dynamic Recrystallization. Materials Science and Engineering: A, 528, 5073-5080.

https://doi.org/10.1016/j.msea.2011.03.008 